\title{
Resource utilization by a sedentary surface deposit feeder, the echiuran worm Maxmuelleria lankesteri
}

\author{
D. J. Hughes ${ }^{1}$, A. D. Ansell ${ }^{1}$, R. J. A. Atkinson ${ }^{2}$ \\ ${ }^{1}$ Dunstaffnage Marine Laboratory, PO Box 3, Oban, Argyll PA34 4AD, Scotland, UK \\ ${ }^{2}$ University Marine Biological Station, Millport, Isle of Cumbrae KA28 0EG, Scotland, UK
}

\begin{abstract}
The feeding behaviour of the shallow-water bonelliid echiuran Maxmuelleria lankesteri is described, based on underwater video recordings made in Loch Sween, Argyll, Scotland. We compare the observed utilization of the sediment surface with the systematic grazing pattern inferred for abyssal echiurans from stellate proboscis traces photographed on the deep-sea floor. M. lankesteri feeds by skimming off the sediment surface during the linear extension of the proboscis from the burrow opening. Successive proboscis extensions did not follow a regular clockwise or anticlockwise path around the burrow opening. The frequency distribution of displacement angles between successive extensions did not differ significantly from random. There was no significant tendency for the proboscis to 'followup' a successful feed by extending in a similar direction the next time, or for the proboscis to avoid a sector in which it had previously been disturbed. This unresponsiveness was shown irrespective of the time elapsed since the preceding extension. The orientation of the proboscis also showed no significant relationship to the direction of water flow. There was usually little or no overlap of proboscis feeding strokes on individual nights, but 1 individual which fed on 9 consecutive nights re-used a significantly greater proportion of the total area grazed than would be expected if feeding strokes were made randomly. The feeding behaviour of $M$. lankesteri differs from the pattern attributed to related deepsea forms in the lack of a systematic proboscis trajectory and in the willingness to re-use previously grazed areas. These differences, if real, may correlate with the trophic status of the habitat. The ability to concentrate feeding effort in specific areas may enable a sedentary deposit-feeder to sequester ephemeral or patchy food resources by 'caching' material within the burrow.
\end{abstract}

KEY WORDS: Maxmuelleria $\cdot$ Echiura $\cdot$ Deposit-feeding $\cdot$ Space utilization $\cdot$ Sea loch

\section{INTRODUCTION}

Areas of sedimentary sea floor often bear a wide variety of tracks and traces produced by the activity of benthic animals (Ewing \& Davis 1967, Heezen \& Hollister 1971). Analysis of these traces can potentially yield much information on patterns of feeding and locomotion, but is often hindered by uncertainty concerning the makers of particular traces.

Features consisting of linear tracks radiating from a central point, usually the site of a burrow opening, have been termed 'spoke burrows', and are one of the most distinctive animal traces seen on soft substrata. Such traces have frequently been photographed in the deep sea (references in de Vaugelas 1989), and are also known in the geological record as trace fossils (Häntzschel 1970, Risk 1973). Spoke burrows have been convincingly attributed to deposit-feeding worms of the phylum Echiura, which feed at the sediment surface by means of a single, extensible proboscis. The stellate feeding trace is created by successive extensions of the proboscis from the burrow opening. This identification is based on observations of shallowwater echiurans (Gislén 1940, Chuang 1962, Risk 1973, Hughes \& Crisp 1976, Hughes et al. 1993), and on deep-sea photographs that fortuitously capture a proboscis in the act of making a feeding trace (Ohta 1984, Bett \& Rice 1993, Boury-Esnault et al. 1993).

Feeding traces have been used to model the foraging strategy of deep-sea echiurans, on the premise that 
precise orientation of successive proboscis strokes will minimize overlaps and thus optimize exploitation of the accessible sediment surface (Ohta 1984, Jumars 1993). These simulations reflect recent interest in the application of optimal foraging models to deposit feeders (Jumars 1993) and in the detection and exploitation of patchy food resources by the deep-sea benthos (Jumars et al. 1990).

Direct observations of deep-sea echiurans feeding are very rare (Ohta 1984, Bett \& Rice 1993), and only general descriptions of the process are available for shallow-water species (Gislén 1940, Chuang 1962, Nyholm \& Bornö 1969, Hughes \& Crisp 1976, Jaccarini \& Schembri 1977, Hughes et al. 1993). Consequently, it is not known whether feeding always proceeds with the regularity assumed in models of the process, or whether the worms are flexible enough to modify their behaviour in response to heterogeneities within the feeding area. The spoke burrows seen in deep-sea photographs represent the cumulative results of activity over an unknown interval, and cannot reveal the sequence and outcome of individual proboscis strokes.

This paper describes the feeding behaviour of Maxmuelleria lankesteri (Herdman), a shallow-water bonelliid echiuran. The observed patterns are used to analyze resource utilization by this sedentary animal constrained to forage within the reach of its feeding appendage, and are compared with the assumptions used to explain the formation of deep-sea spoke burrows.

\section{METHODS}

Maxmuelleria lankesteri is a large bonelliid echiuran that occurs in many of the sea lochs of western Scotland (Hughes et al. 1993). Like other echiurans, M. lankesteri has a unsegmented, saccate body (up to $18 \mathrm{~cm}$ long in contracted state), and a highly extensible, ribbon-like proboscis. The animal inhabits a narrow, sinuous burrow up to $2 \mathrm{~m}$ long and extending up to $70 \mathrm{~cm}$ deep in the sediment (Nickell et al. in press a). At present it is uncertain whether the burrow has 1 or 2 openings to the surface. Visible openings are often at the apex of a mound created by active ejection of sediment from the burrow (Hughes et al. 1993).

Underwater television observations of Maxmuelleria lankesteri were carried out in Loch Sween, Argyll, Scotland, a shallow sea loch (maximum depth $38 \mathrm{~m}$ ) with a substratum composed largely of organic-rich fine muds (Nickell et al. in press b). Studies were carried out at 2 sites in the loch $\left(56^{\circ} 1.4^{\prime} \mathrm{N}, 5^{\circ} 36.9^{\prime} \mathrm{W}\right.$ and $56^{\circ} 2.4^{\prime} \mathrm{N}, 5^{\circ} 34^{\prime} \mathrm{W}$ ), both located approximately $150 \mathrm{~m}$ offshore in 10 to $12 \mathrm{~m}$ of water.

Observations were made using an Osprey Electronics Ltd OE1356 underwater video camera mounted vertically in a lightweight metal frame. Two OE1132 underwater lamps with $300 \mathrm{~W}$ quartz iodide bulbs provided illumination. Because Maxmuelleria lankesteri was known to be highly light-sensitive, infrared filters were placed over the lamps to exclude visible light. The video camera and lamps were connected to the shore by cable, and powered either by a portable generator or from an accessible domestic electricity supply. The camera frame was deployed from a small boat and positioned over a burrow opening by divers. The height of the camera lens above the substratum varied from 70 to $100 \mathrm{~cm}$ on different deployments. When mounted high, the camera naturally had a wider field of view, and in some cases it was possible to observe 2 neighbouring burrow openings simultaneously. Recordings were made in time-lapse with a VHS videocassette recorder. Camera deployments were made at intervals between March 1991 and November 1992, for periods ranging from 1 to $23 \mathrm{~d}$ depending on available facilities and other logistical factors.

Data on feeding behaviour were obtained from the video recordings by tracing the outline of each proboscis stroke from a monitor screen onto acetate sheet. The timing and outcome of each emergence was noted, and the angles between successive strokes measured using a protractor. The frequency of angular displacement between consecutive strokes was recorded in $30^{\circ}$ sectors from 0 to $180^{\circ}$ and compared with the frequencies expected under a null hypothesis of random emergence direction.

Regions of sediment surface skimmed by the proboscis were traced onto paper and their areas determined gravimetrically. The actual areas represented were calculated using a conversion factor obtained from a scale bar placed in the camera's field of view during each deployment. We also measured the extent of overlaps between proboscis strokes. The feeding area potentially available to each individual was considered as the circle described by the proboscis at its maximum observed extension. Space utilization within the feeding circle was analyzed by calculating the binomial probabilities of a given point remaining uncontacted, or of being swept once, twice or more by the observed number of feeding extensions, assuming random emergence direction. The expected values were then compared with the extent of overlap actually observed.

\section{RESULTS}

\section{General observations}

During 1991-1992, 9 camera deployments were made and 13 worms were observed. Proboscis emergence was found to be strictly nocturnal, with individuals 
feeding on average about 1 night in 3 . Up to 17 proboscis extensions were recorded from a single burrow opening on an active night, with a mean of 7 . Proboscis emergence occurred at irregular intervals during the night, with no rhythmic pattern. Observed proboscides ranged from 7.2 to $25.4 \mathrm{~cm}$ at maximum extension. A total of 233 proboscis extensions were observed, but only $118(51 \%)$ of these resulted in the intake of sediment to the burrow. About $30 \%$ of the extensions were curtailed due to contact with crabs, ophiuroids or other mobile epifauna which were abundant at the study sites. When touched, the proboscis withdrew rapidly into the burrow, shedding any collected material. In the remaining $20 \%$ of cases the echiuran was not disturbed, but retracted its proboscis without collecting any sediment (Fig. 1a). The number of sediment in- takes to the burrow per active night ranged from 0 (the worm extended its proboscis but failed to feed) to 10 , with a mean of 4 .

The method of sediment grazing has been described in detail elsewhere (Hughes et al. 1993). Uptake is achieved by a 'skimming' of the sediment surface during the linear extension of the proboscis (Fig. 1b). The proboscis then retracts, pulling the collected material down into the burrow. The entire process typically lasts about $8.5 \mathrm{~min}$. The skimming action usually does not begin until the proboscis tip has extended some distance from the burrow opening. The following analyses of space utilization and proboscis overlap are therefore based on the areas from which sediment was actually collected, rather than the full length of each proboscis track. The feeding process can lead to the
Fig. 1. Maxmuelleria lankesteri. (a) Still photograph taken from an underwater video recording made in Loch Sween, Scotland, showing the proboscis extending from a burrow opening. The proboscis is not grazing the sediment surface. The scale bar to the right of the burrow opening is marked in $\mathrm{cm}$. (b) A feeding proboscis extension by the same individual. The distal half of the extended proboscis is covered by a layer of material skimmed from the sediment surface
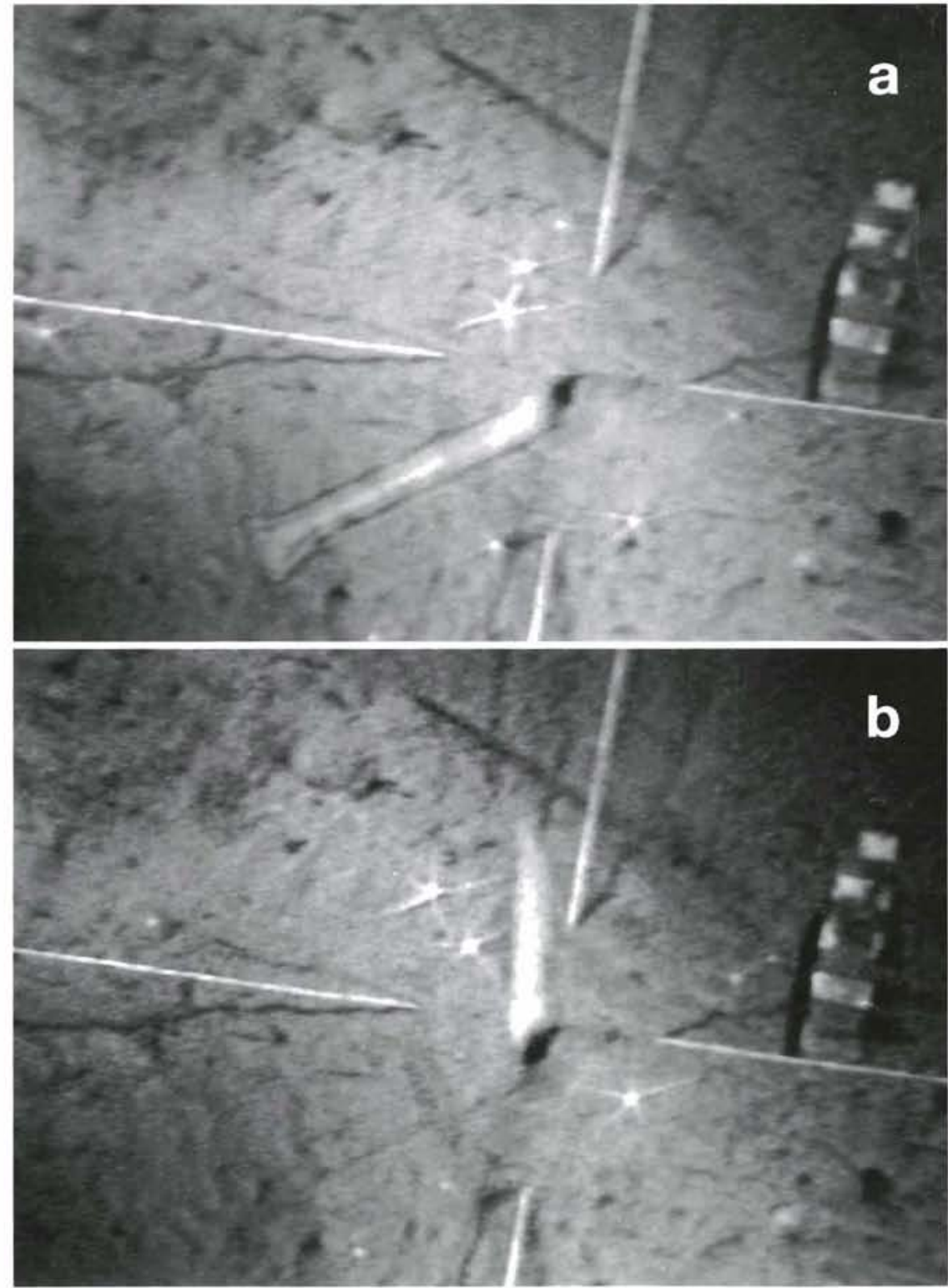
formation of 'spoke burrow' traces similar to those photographed in the deep sea, but due to the abundance of active epifauna in Loch Sween these traces tend to be erased rapidly and are therefore not often seen by divers.

\section{Direction of proboscis emergence}

Successive proboscis extensions never showed a regular clockwise or anticlockwise progression around the feeding circle. Displacement angles between consecutive strokes varied over the entire possible range of 0 to $180^{\circ}$. Considering all consecutive pairs $(n=196)$, the frequency distribution of displacement angles in $30^{\circ}$ sectors did not differ significantly from random $\left(\chi^{2}=7.319\right.$ with $\left.5 \mathrm{df}, \mathrm{p}>0.05\right)$ (Fig. 2a). There was therefore no consistent orientation of emergence direction or predetermined spacing of proboscis strokes. However, on individual nights of activity there was a significant tendency for the second emergence in a sequence to occur at a large angle from the first. This tendency was non-significant $(p<0.10)$ when frequencies in $30^{\circ}$ sectors were analyzed, but was enhanced when observations were pooled into three $60^{\circ}$ sectors $\left(\chi^{2}=9.169\right.$ with 2 df, $\left.\mathrm{p}<0.05\right)$. Of 29 second emergences, $17(59 \%)$ were displaced 120 to $180^{\circ}$ away from the first, compared with only 9.7 expected in this category if emergence direction were random. However, the orientations of the third, fourth, fifth and sixth emergences in each sequence to their preceding strokes did not differ significantly from random, whether classed in $30^{\circ}$ or $60^{\circ}$ sectors.

The 3 observed outcomes of a proboscis stroke (successful feeding, disturbance, or undisturbed, nonfeeding retraction) made it possible to analyze the consequences of each for the next emergence. In none of the 3 categories did the orientation of the following strokes depart significantly from random (Fig. $2 \mathrm{~b}$ to d). There was no tendency for the worms to 'follow-up' a successful feeding extension by sending the next proboscis stroke in a similar direction $\left(\chi^{2}=4.651\right.$ with $5 \mathrm{df}$, $\mathrm{p}>0.05, \mathrm{n}=89$ emergences), or to respond to disturbance by avoiding the sector in which it had occurred ( $\chi^{2}=9.714$ with $5 \mathrm{df}, \mathrm{p}>0.05, \mathrm{n}=42$ emergences). This apparent unresponsiveness to the outcome of the most recent proboscis stroke was not a function of the time elapsed since that event (Fig. 3). There was no significant relationship between the time elapsed after a successful feed and the displacement angle of the next proboscis stroke (Spearman rank correlation $=-0.204$ ), over a time scale of $2.3 \mathrm{~min}$ to $6.7 \mathrm{~h}$. There was also no significant correlation between the period following a disturbed extension and the displacement of the subsequent extension (Spearman rank correlation = -0.076 ). Time intervals following disturbances ranged from $2.5 \mathrm{~min}$ to $3.5 \mathrm{~h}$.

The direction of proboscis emergence was not consistently related to the prevailing current direction. Current direction could sometimes be determined
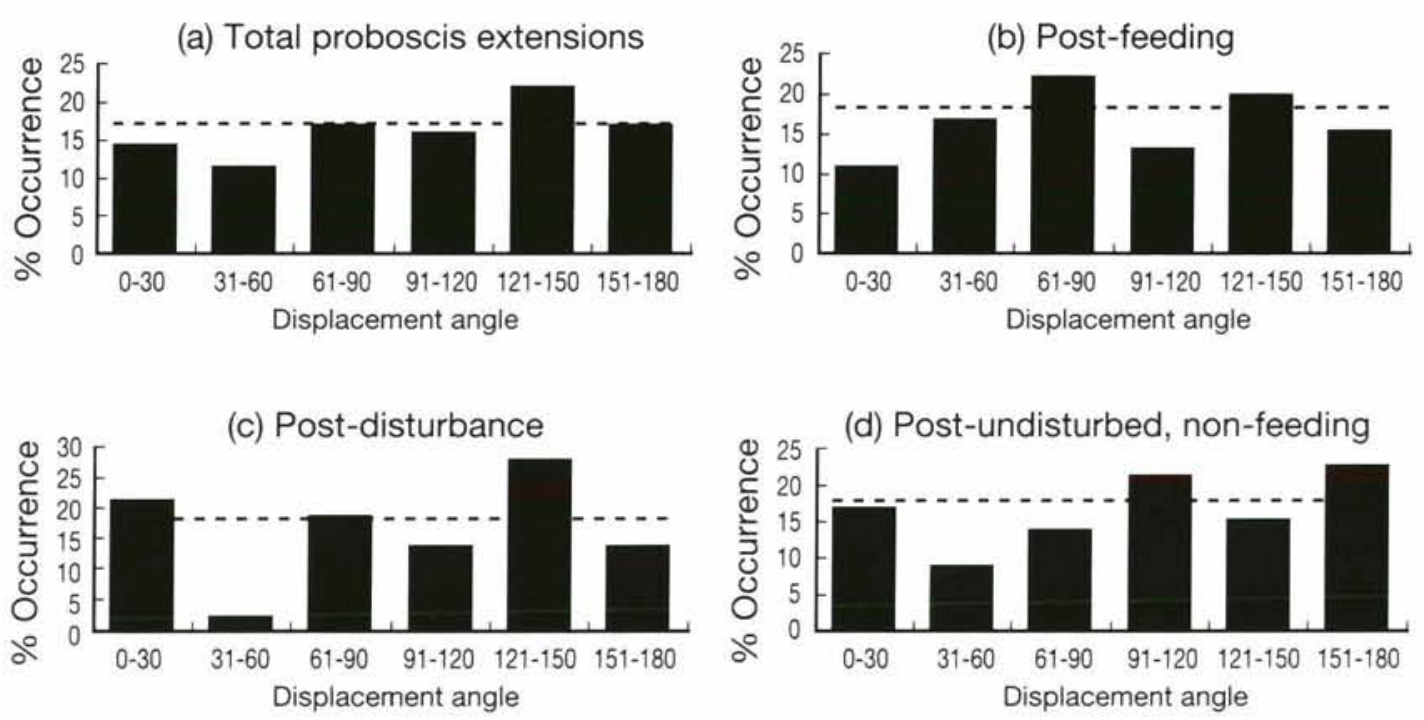

Fig. 2. Maxmuelleria lankesteri. Percentage occurrence of displacement angles between successive proboscis extensions, measured in $30^{\circ}$ sectors. The horizontal dashed line on each histogram denotes the $16.7 \%$ occurrence to be expected if each proboscis extension is orientated at random to the preceding one. (a) Distribution of displacement angles for all observed proboscis extensions ( $\mathrm{n}=196$ ); (b) displacement angles for extensions following feeding strokes ( $\mathrm{n}=89$ ); (c) displacement following extensions on which the proboscis retracted due to disturbance $(n=42)$; (d) displacement following extensions on which the proboscis withdrew undisturbed, without collecting sediment $(n=65)$ 

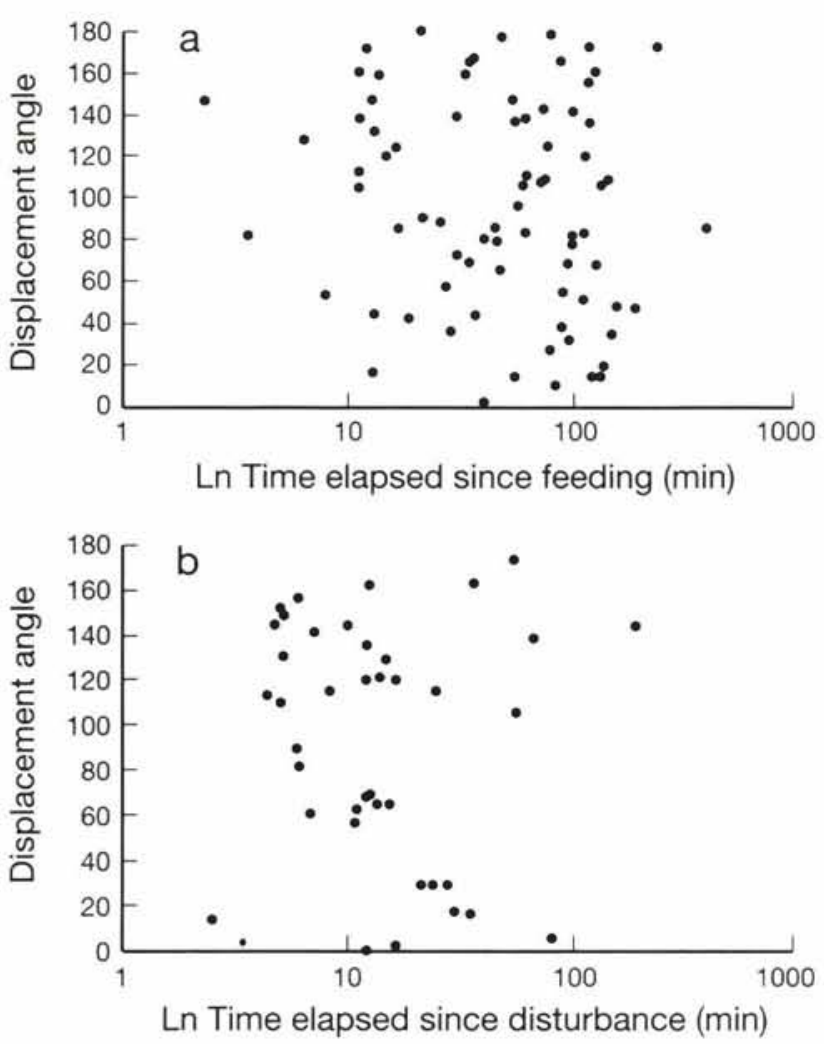

Fig. 3. Maxmuelleria lankesteri. Displacement angle between successive proboscis strokes as a function of the time elapsed between them (on a logarithmic scale). (a) Post-feeding extensions, (b) post-disturbance extensions

from the video recordings by observing the passage of suspended particles under the camera. Tidal currents at the study sites were weak, with a maxmimum observed value of about $4 \mathrm{~cm} \mathrm{~s}^{-1}$. The orientation of the proboscis relative to water flow was measurable in 127 cases, and showed no significant departure from random (Fig. 4) $\left(\chi^{2}=7.871\right.$ with $\left.5 \mathrm{df}, \mathrm{p}>0.05\right)$.

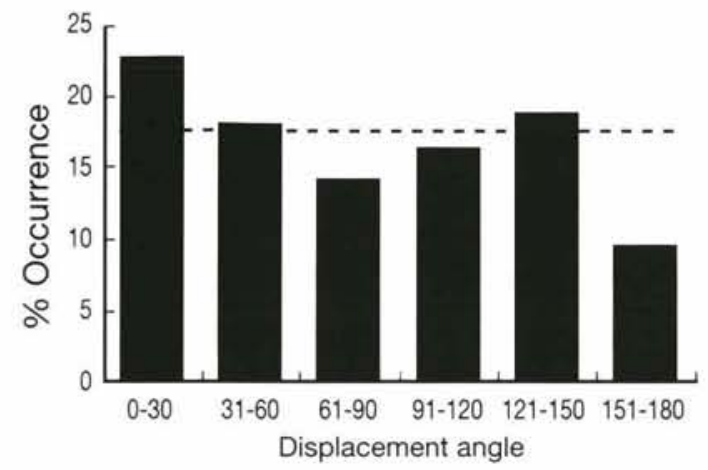

Fig. 4. Maxmuelleria lankesteri. Percentage occurrence of displacement angles between the extended proboscis and the direction of tidal flow at that time $(\mathrm{n}=127)$. The horizontal dashed line denotes the $16.7 \%$ occurrence expected if the proboscis is randomly orientated with respect to the current

\section{Utilization of space within the feeding circle}

Potential feeding circles, estimated from the maximum observed proboscis extensions, ranged from 162.9 to $2026.8 \mathrm{~cm}^{2}$ for the smallest and largest individuals. Considering the potential feeding area as a circle assumes that the proboscis is capable of equal extension in all directions, an assumption supported by observations of feeding activity. On individual nights of feeding, between 1.2 and $18.1 \%$ of the available sediment surface was grazed by the proboscis, with a mean value of $7.3 \% \pm 5.2 \mathrm{SD}$. The highest relative space utilization was achieved by the animal with the smallest observed proboscis (maximum recorded extension $7.2 \mathrm{~cm}$ ).

Three individuals were observed feeding on several consecutive nights. The cumulative figures for total space utilization within their feeding circles were $31.4 \%$ (October 1991, 2 nights), 12.9\% (July 1992, 3 nights) and $42.9 \%$ (August 1992, 9 nights). The high figure of $31.4 \%$ of available space utilized in only 2 nights of feeding was achieved by the small individual mentioned above. The feeding behaviour of this specimen was notable in that the proboscis began to skim the sediment surface almost as soon as it emerged from the burrow opening, and therefore collected material along almost all of its track. This pattern was occasionally seen in other individuals, but more typically the proboscis extended some way from the burrow opening before starting to pick up sediment.

Within individual feeding nights there was usually little overlap of areas grazed by the proboscis. There was no overlap in 10 out of 19 nights on which feeding was observed. The maximum overlap on a single night amounted to $12.4 \%$ of the area utilized by the proboscis. Some overlap also occurred between feeding tracks made on consecutive nights. Of the total sediment area utilized by the small worm observed for 2 nights in October 1991, $13.7 \%$ was grazed twice. The July 1992 individual re-utilized $12.0 \%$ of the total area skimmed in 3 nights of feeding. The individual observed in August 1992 fed on 9 consecutive nights, and so gave much more opportunity to record the pattern of space utilization. Between 0 and $34.2 \%$ (mean $11.2 \% \pm 13.2 \mathrm{SD}$ ) of the area utilized on a given night overlapped with tracks made on the preceding night. Of the total area grazed by the proboscis of this animal, over half $(54.3 \%)$ was utilized more than once (Fig. 5 ). The area swept twice constituted $34.6 \%$ of the totali $14.4 \%$ was used 3 times and $5.3 \% 4$ or more times. Small patches received up to 6 proboscis strokes.

The August 1992 animal made a total of 43 feeding strokes (Fig. 6). On some nights (e.g. nights 5 and 6) sediment intakes were clustered in a restricted sector of the feeding circle, whereas on others (e.g. nights 3 , 


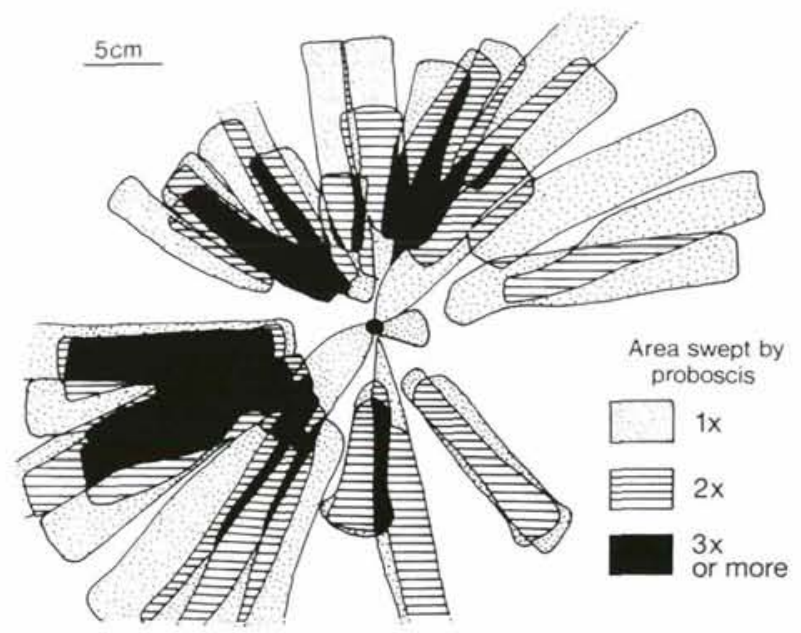

Fig. 5. Maxmuelleria lankesteri. Diagram showing the cumulative utilization of surface sediment by a worm observed feeding on 9 consecutive nights in August 1992. The central solid circle marks the burrow opening

7 and 9) they were more dispersed. The overlap of feeding strokes within individual nights was small (maximum on night 7, area grazed $12.4 \%$ ). The mean area of a proboscis feeding stroke was $37.1 \mathrm{~cm}^{2}$, proportionally equivalent to 0.018 of the potential feeding circle. If 43 strokes of this size were made at random, the probability of any point in the circle remaining uncontacted by the proboscis would be $(0.982)^{43}$, or 0.458 . One would thus expect $45.8 \%$ of the feeding circle to remain unutilized. The unutilized portion actually constituted $57.1 \%$ of the available area, indicating a non-random clustering of feeding strokes within the circle. The occurrence of selective feeding was confirmed by comparing the observed and expected overlap of proboscis strokes. Assuming 43 randomly directed proboscis strokes of area $37.1 \mathrm{~cm}^{2}$, binomial proportions of the feeding circle remaining unutilized, grazed once or grazed more than once would be $0.458,0.361$ and 0.180 , respectively. The corresponding observed proportions were $0.571,0.196$ and 0.233 . Converting these proportions to actual areas within the feeding circle of $2026.8 \mathrm{~cm}^{2}$ and comparing observed and expected values showed that the amount of overlapped space was significantly greater than expected $\left(\chi^{2}=38.311\right.$ with $\left.1 \mathrm{df}, \mathrm{p}<0.001\right)$. To counter the possible objection that some proboscis strokes extended outside the camera's field of view, leading to an underestimate of space utilization, the analysis was repeated using only the rectangular area fully visible to the camera (Fig. 6). This procedure yielded the same result, indicating that sediment was selectively taken up from localized areas within the feeding range.

Two other observed individuals appeared to feed selectively. The 15 feeding strokes made over 3 nights by the July 1992 individual were all located in one half of its feeding circle (Fig. 7a). The proboscis was extended into the other half of the circle, but no sediment was taken up there. Some overlap of strokes occurred in the preferred half of the circle, but its extent was not significantly different from that

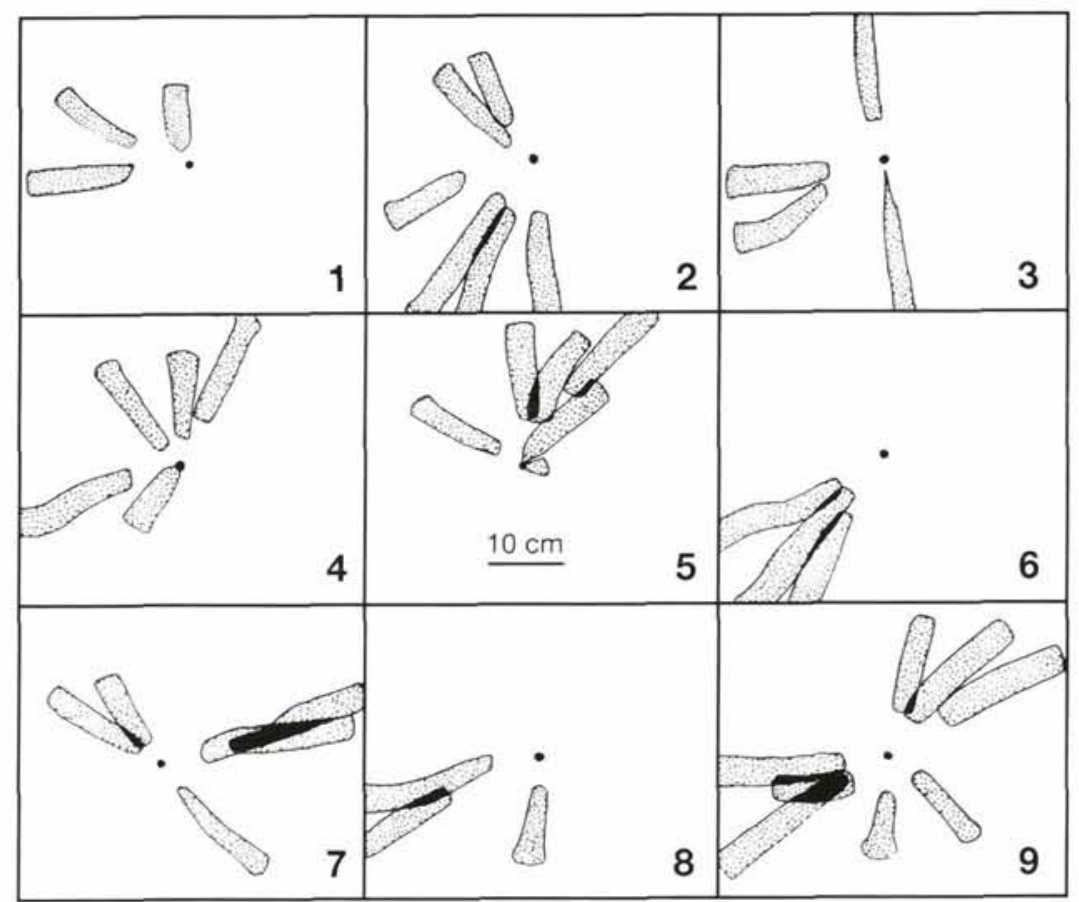

Fig. 6. Maxmuelleria lankesteri. Space utilization on individual nights by the individual observed in August 1992. Each rectangular cell represents the field of view of the underwater video camera. The central black spot in each cell indicates the position of the burrow opening. Stippled patches represent areas of sediment grazed by the proboscis. Areas of proboscis overlap are shown in black 

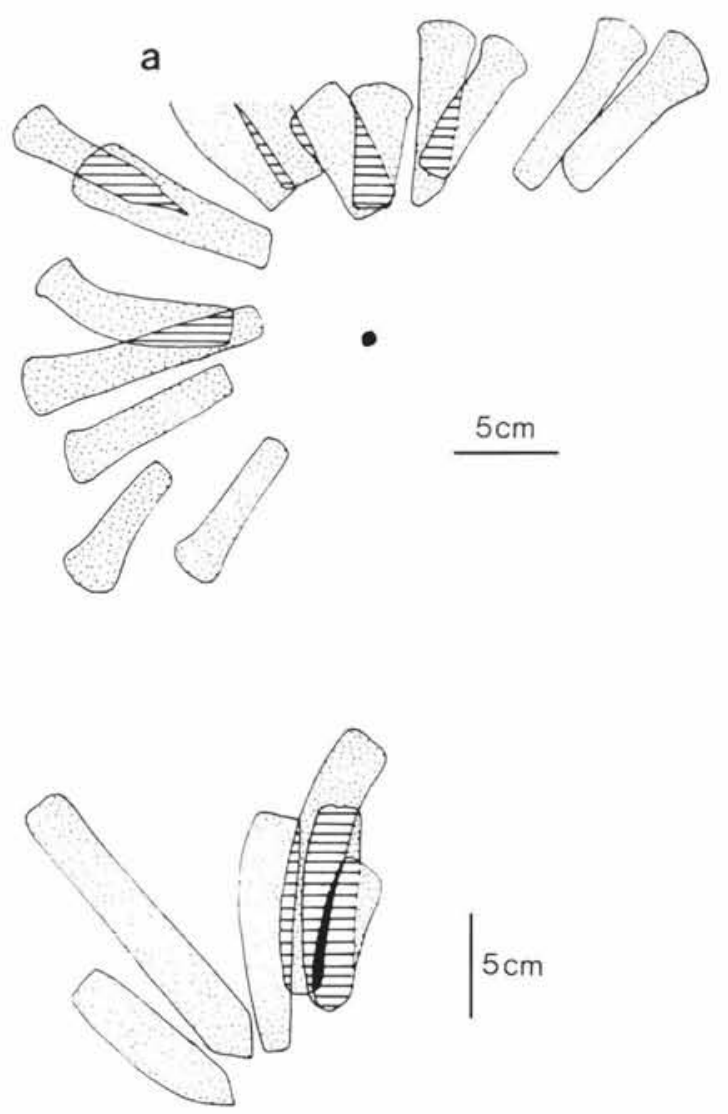

b

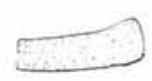

Fig. 7. Maxmuelleria lankesteri. Surface sediment utilization by 2 individuals observed for (a) 3 nights in July 1992, and (b) 1 night in October 1991. Stippled, hatched and solid black areas denote intensity of sediment grazing as in Fig. 5

expected under the null hypothesis of random feeding $\left(\chi^{2}=1.715\right.$ with $\left.1 \mathrm{df}, \mathrm{p}>0.05\right)$. The larger worm observed in October 1991 made 7 feeding extensions ( 1 of which was curtailed by disturbance), of which 6 were tightly clustered in a sector comprising about $70^{\circ}$ of the feeding circle (Fig. 7b). Again, the worm's proboscis explored more widely within the accessible area but did not collect sediment. The clustering of 6 feeding strokes resulted in a degree of overlap significantly greater than that expected if feeding extensions were made at random $\left(\chi^{2}=79.282\right.$ with $\left.1 \mathrm{df}, \mathrm{p}<0.001\right)$.

\section{DISCUSSION}

The foraging behaviour of Maxmuelleria lankesteri is clearly not organized according to a rigidly programmed set of 'rules'. Proboscis emergence direction showed little deviation from random, and successive strokes did not show the precise sequential orientation attributed to deep-sea echiurans (Ohta 1984). Nor did the worms show the expected aversion to overlapping their previous proboscis strokes. On any single night of feeding the number of feeding strokes was usually low, and their apparently random orientations resulted in little or no overlap. However, when feeding occurred on several consecutive nights there could be extensive re-use of previously grazed areas. The large individual filmed in October 1991 showed a significant clustering of feeding effort on 1 night of activity.

These observations do not demonstrate that deepsea echiurans lack a systematic foraging strategy, but they do illustrate the need for caution when inferring patterns of behaviour from traces left by the process. Ohta (1984) found very little overlap of proboscis tracks in 'saturated' feeding traces (those with almost complete utilization of the accessible sediment surface) and attributed this pattern either to a geneticallydetermined proboscis displacement angle or to chemotactic avoidance of areas previously contacted by the proboscis. The hypothesis of a predetermined displacement angle receives no support from the observations of Maxmuelleria lankesteri, perhaps suggesting that the second mechanism is more likely. The unidentified deep-sea echiuran filmed by Bett \& Rice (1993) fed by a 'sweeping' motion of a highly elongated proboscis, quite different from the linear proboscis extension of $M$. lankesteri or deep-sea spoke-burrow formers. There was very little overlap between the 8 discrete 'sweeps' observed. Ohta (1984) quotes Seilacher's hypothesis that systematic foraging behaviour is required in nutrient-poor sediments where organisms are under strong selection pressure to efficiently utilize the available surface, whereas in richer environments deposit-feeders can afford to graze more haphazardly. So far, there are insufficient detailed observations of grazing patterns in a variety of habitats to determine whether this generalization can be accepted, but there is some evidence to support it. The irregular foraging pattern of $M$. lankesteri correlates with the high organic carbon content ( 3.5 to $4.0 \%$ ) of Loch Sween sediments. In contrast, the depositfeeding crab Scopimera inflata grazes nutrient-poor sediment around its burrow opening in a manner analagous to the linear proboscis extension of an echiuran, and proceeds in a rigidly stereotyped clockwise or anticlockwise path around the burrow (Zimmer-Faust 1987, 1989).

The loosely-organized foraging behaviour of Maxmuelleria lankesteri apparently confers the ability to detect and exploit gradients in the nutritional quality of the sediment accessible to the proboscis. This inference is supported by the clustering and higherthan-expected overlap of proboscis strokes observed 
in some individuals. This feeding selectivity is apparently not achieved through any 'memory' of patch location, since the proboscis showed no significant tendency to return to an area grazed on the previous extension. Rather, it seems that the proboscis is extended at random, but has a higher probability of picking up sediment if its path takes it onto a favourable patch. This selectivity implies that the proboscis is sensitive to the nutritional quality of the surface sediment, presumably by detection of chemical cues. Chemotactic responses have been demonstrated in echiurans. Jaccarini \& Schembri (1977) found that the proboscis of Bonellia viridis spent more time grazing on sand grains artificially enriched with a flagellate (Isochrysis sp.) than on clean control grains, although enrichment with some other plant and animal materials elicited no significant response.

The ability to concentrate feeding effort on limited areas within the feeding circle may facilitate 'caching' - the sequestration of patchy or ephemeral food resources by rapid uptake and storage within the burrow. Caching has been proposed as a possible nutritive strategy for sedentary deposit feeders in the deep sea (Plante et al. 1990), enabling them to take advantage of episodic pulses of food material arriving on the sea floor. Some evidence of this behaviour has been found in deep-sea sipunculans (Graf 1989, Jumars et al. 1990). Although the more constant and abundant food resources available to a shallow-water echiuran such as Maxmuelleria lankesteri may not place such a premium on sequestration, such behaviour might be of use in exploiting localized patches of detritus accumulating in a current 'shadow' at the base of the mound surrounding the burrow opening, or in nearby surface depressions (Yager et al. 1993). Storage of material in the form of faecal pellets has been suggested as a possible caching mechanism (Jumars et al. 1990). M. lankesteri deposits faecal pellets in the lining of its burrow (Kershaw et al. 1984, pers. obs.), but it is not known whether the echiuran habitually re-ingests them.

In conclusion, Maxmuelleria lankesteri shows a feeding pattern far less stereotyped than that proposed for closely related species inhabiting the deep sea. Whether this pattern is general for echiurans, or whether differences exist correlated with the trophic status of the habitat, can only be determined by comparable observations in the deep sea. This study of $M$. lankesteri was intended to provide baseline data on the behaviour of undisturbed worms in natural conditions. Our interpretation of the feeding strategy is based solely on observation, but incorporates testable predictions which could form the basis of future studies. Measurements of sediment nutritive quality could be made at points around burrow openings to test the existence of small-scale heterogeneity, while experimental enrichment of small areas could be performed to test whether the echiurans are responsive to patchiness of this kind.

Acknowledgements. We are particularly grateful to Dr Owen Paisley of Scottish Natural Heritage for providing facilities for video observations in Loch Sween. The diving teams of the Dunstaffnage Marine Laboratory and the University Marine Biological Station, Millport also provided essential field assistance throughout this project. We thank 2 referees for their constructive comments. This project was funded by the Ministry of Agriculture, Fisheries and Food, UK.

\section{LITERATURE CITED}

Bett, B. J., Rice, A. L. (1993). The feeding behaviour of an abyssal echiuran revealed by in situ time-lapse photography. Deep Sea Res. I 40: 1767-1779

Boury-Esnault, N., Harmelin, J.-G., Vacelet, J. (1993). Les abysses Méditerranéennes à vingt mètres de profondeur? La Recherche 256 Suppl. Juillet-Août 1993, 24: 848-851

Chuang, S. H. (1962). Feeding mechanism of the echiuroid, Ochetostoma erythrogrammon Leuckart and Rueppell, 1828. Biol. Bull. 123: 80-85

de Vaugelas, J. (1989). Deep-sea lebensspuren: remarks on some echiuran traces in the Porcupine Seabight, northeast Atlantic. Deep Sea Res. 36: 975-982

Ewing, M., Davis, R. A. (1967). Lebensspuren photographed on the ocean floor. In: Hersey, J. B. (ed.) Deep-sea photography. John Hopkins, Baltimore, p. 259-294

Gislén, T. (1940). Investigations on the ecology of Echiurus. Lunds Univ. Arsskr. Adv. 2, 36: 1-39

Graf, G. (1989). Benthic-pelagic coupling in a deep-sea benthic community. Nature 341: 437-439

Häntzschel, W. (1970). Star-like trace fossils. In: Crimes, T. P., Harper, J. C. (eds.) Trace fossils. Seel House Press, Liverpool, p. 201-214

Heezen, B. C., Hollister, C. D. (1971). The face of the deep. Oxford University Press, New York

Hughes, D. J., Ansell, A. D., Atkinson, R. J. A., Nickell, L. A. (1993). Underwater television observations of surface activity of the echiuran worm Maxmuelleria lankesteri (Echiura: Bonelliidae). J, nat. Hist. 27: 219-248

Hughes, R. N., Crisp, D. J. (1976). A further description of the echiuran Prashadus pirotansis. J. Zool., Lond. 180: 233-242

Jaccarini, V., Schembri, P. J. (1977). Feeding and particle selection in the echiuran worm Bonellia viridis (Echiura: Bonelliidae). J. exp. mar. Biol. Ecol. 28: 163-181

Jumars, P. A. (1993). Gourmands of mud: diet selection in marine deposit feeders. In: Hughes, R. N. (ed.) Diet selection - an interdisciplinary approach to foraging behaviour. Blackwell Scientific Publications, Oxford, p. $124-156$

Jumars, P. A., Mayer, L. M., Deming, J. W., Baross, J. A., Wheatcroft, R. A. (1990). Deep-sea deposit-feeding strategies suggested by environmental and feeding constraints. Phil. Trans. R. Soc. A 331: 85-101

Kershaw, P. J., Swift, D., Pentreath, R. J., Lovett, M. B. (1984). The incorporation of plutonium, americium and curium into the Irish Sea seabed by biological activity. Sci. total Environ. 40: 61-81

Nickell, L. A., Atkinson, R. J. A., Hughes, D. J., Ansell, A. D., Smith, C. J. (in press a). Burrow morphology of the 
echiuran worm Maxmuelleria lankesteri (Echiura: Bonelliidae), and a brief review of burrow structure and related ecology of the Echiura. J. nat. Hist.

Nickell, L. A., Hughes, D. J., Atkinson, R. J. A. (in press b). Megafaunal bioturbation in organically enriched Scottish sea lochs. In: Proc. 28th Eur. Mar. Biol. Symp. Hersonissos, Crete. Olsen and Olsen, Fredensborg

Nyholm, K.-G., Bornö, C. (1969). The food uptake of Echiurus echiurus Pallas. Zool. Bidr. Upps. 38: 249-254

Ohta, S. (1984). Star-shaped feeding traces produced by echiuran worms on the deep-sea floor of the Bay of Bengal. Deep Sea Res. 31: 1415-1432

Plante, C. J., Jumars, P. A., Baross, J. A. (1990). Digestive

This article was presented by R. N. Hughes (Senior Editorial Advisor), Bangor, United Kingdom associations between marine detritivores and bacteria A. Rev. Ecol. Syst. 21: 93-127

Risk, M. (1973). Silurian echiuroids: possible feeding traces in the Thorold sandstone. Science 166: 994-995

Yager, P. L., Nowell, A. R. M., Jumars, P. A. (1993). Enhanced deposition to pits: a local food source for benthos. J. mar. Res. 51: 209-236

Zimmer-Faust, R. K. (1987). Substrate selection and use by a deposit-feeding crab. Ecology 68: 955-970

Zimmer-Faust, R. K. (1989). Foraging strategy of a depositfeeding crab. In: Hughes, R. N. (ed.) Behavioural mechanisms of food selection. NATO ASI series, Vol. G20. Springer-Verlag, Berlin, p. 557-568

Manuscript first received: March 24, 1994

Revised version accepted: June 3, 1994 